\title{
A TRADUÇÃO DO CONHECIMENTO CIENTÍFICO NAS MATÉRIAS DE SAÚDE DA REVISTA VEJA
}

\author{
The translation of scientific knowledge on bealth news of Magazine Veja
}

\begin{abstract}
Lia Hecker Luz
Mestre em Comunicação Social pela Pontifícia Universidade Católica do Rio Grande do Sul (PUCRS), professora do curso de Jornalismo da Universidade do Vale do Rio dos Sinos (UNISINOS), São Leopoldo, RS - Brasil, e-mail: liahluz@hotmail.com
\end{abstract}

\begin{abstract}
Resumo
Este trabalho se propõe a analisar matérias sobre saúde publicadas nas edições de janeiro a junho de 2005 da revista $V e j a$, para verificar se as publicações alcançam o objetivo do jornalismo científico de traduzir conhecimentos específicos para uma linguagem acessível ao público massivo, e se apresentam os assuntos de forma contextualizada, interpretando-os. O percurso metodológico foi guiado pela análise de conteúdo, como proposto por Laurence Bardin, com o auxílio da catalogação realizada com o programa Winisis, da Unesco. Através da análise dos textos publicados em Veja, verifica-se que a revista traduz e contextualiza o conhecimento científico, indo além da simples notificação, situando-se no detalhamento, no questionamento de causa e efeito, na interpretação e no impacto, dando uma nova dimensão narrativa aos assuntos de saúde. Para tornar as informações mais compreensíveis, Veja também utiliza em uma parcela significativa de matérias o recurso da humanização, levando os temas até o ambiente do leitor.
\end{abstract}

Palavras-chave: Comunicação. Jornalismo científico. Saúde. Veja.

\begin{abstract}
This paper aims to analyze the news on health ran on the editions from January to June of 2005 of Veja magazine, to verify if the publication reach the goal of scientific journalism of translating specific knowledge into an accessible language to the mass public, and if it presents the subjects in a contextualized way, interpreting it. The methodological path is guided by content analyses, as proposed by Laurence Bardin, with the assistance of the electronic cataloguing of software Winisis, by Unesco. By the analyses of the news ran in Veja, it's possible to verify that the magazine translate and contextualize the scientific knowledge, going further than the simple notification, situating it on the details, on the cause and effect wondering, on the interpretation and on the impact, giving a new narrative dimension to health subjects. To make the stories more comprehensible, Veja also uses in a significant part of the stories the humanization resource, bringing the themes to the reader's environment.
\end{abstract}

Keywords: Communication. Scientific Journalism. Health. Veja Magazine. 


\section{INTRODUÇÃO}

Uma das características do nosso tempo são as modificações explosivas de costumes, saberes, normas, linguagens, técnicas, modos de comportamento e, em geral, de toda a vida cotidiana. Assim também ocorre com a ciência e a medicina. O jornalismo científico procura preencher essas lacunas ao traduzir e contextualizar conhecimentos específicos, tendo por objetivo educar, orientar e informar o grande público sobre assuntos referentes, por exemplo, aos cuidados com a saúde.

A educação formal, dentro de sala de aula ou mesmo nos consultórios médicos e de outros profissionais da saúde, proporciona oportunidades de aprendizado sobre o corpo, sua anatomia e fisiologia, as doenças e sua prevenção. Mas é a educação informal - aquela realizada por meio da divulgação de matérias em jornais, revistas, rádio, TV e Internet - que fornece a maior parte das informações que as pessoas recebem sobre temas de saúde. A divulgação da ciência em veículos de comunicação possibilita a um maior número possível de pessoas o acesso às informações científicas.

No entanto, a divulgação deve ser feita de maneira clara e contextualizada, para que o público consiga entender, por exemplo, se serão benéficos os resultados de um novo tratamento ou da mudança de hábitos e comportamentos. Somente assim, bem informados, os cidadãos podem tomar decisões conscientes. Nem sempre a divulgação de conhecimentos específicos, entretanto, é feita de modo esclarecedor. Muitas vezes, pode gerar ainda mais dúvidas e incertezas nos leitores.

O objetivo geral deste estudo é identificar se a revista semanal $V e j a$, escolhida por ser o veículo de mídia impressa com maior alcance no país, traduz o conhecimento científico, com seus jargões técnicos, para uma linguagem acessível ao público massivo. Além disso, busca identificar se nas matérias analisadas aparecem elementos do jornalismo interpretativo, no qual se insere o jornalismo científico, tais como a contextualização e a humanização dos relatos.

\section{MATERIAIS E MÉTODOS}

Para este estudo, que visa a conhecer como o conhecimento científico é divulgado em um meio de comunicação massivo e não-especializado, se optou pela revista semanal de assuntos gerais com maior circulação no país, ou seja, a revista $V$ eja. A revista foi lançada em setembro de 1968, em plena época de ditadura no Brasil, com tiragem de 700 mil exemplares e o objetivo de oferecer aos leitores uma seleção ordenada e concisa dos fatos essenciais da semana em todos os campos do conhecimento. Hoje, as assinaturas correspondem a aproximadamente $80 \%$ da venda dos cerca de 1,2 milhões de exemplares semanais. É atualmente a quarta revista de informação mais vendida no mundo, atrás somente de três norte-americanas: Time, Newsweek, e US News \& World Report.

O corpus se constitui de todas as matérias sobre saúde com pelo menos uma página de extensão veiculadas nas 26 edições de $V$ eja do primeiro semestre de 2005 , entre $1^{\circ}$ de janeiro e 30 de junho, somando um total de 50 matérias. Não foram incluídas as matérias com tamanho inferior a uma página, por não serem consideradas matérias e, sim, notas ou, como comumente usado no jargão jornalístico, materiolas.

Como base de dados e como operador informatizado para o tratamento dos dados levantados segundo a metodologia de Análise de Conteúdo proposta porLaurence Bardin, foi utilizado o programa Winisis. O programa foi usado como base de dados porque as informações constantes nas matérias foram armazenadas, com o auxílio do software, em fichas catalográficas especialmente construídas para o projeto. E foi utilizado como operador informatizado uma vez que o próprio programa executou as buscas e os cruzamentos dos resultados da pesquisa. A análise foi dividida em duas etapas: a análise simples, em que os dados são apresentados de forma direta, e a análise cruzada, em que ocorre o cruzamento de variáveis.

\section{RESULTADOS}

\section{Linguagem e humanização}

Um dos principais problemas encontrados pelos redatores de ciência é fazer com que as notícias cheguem ao leitor em uma linguagem simples, diferente daquela específica na qual o conhecimento científico foi elaborado. Para atingir a meta de alcançar um texto de fácil compreensão para o público, o jornalista necessita, antes, compreender bem o tema. Por isso, sugere-se que, ao término da explanação do cientista, ele utilize suas próprias palavras para descrever aquilo que acabou de ouvir. Assim, o cientista poderá analisar se o repórter assimilou o 
conhecimento de forma correta ou não. Em caso negativo, o jornalista deverá pedir nova explicação, para que as informações não saiam deturpadas ou incompletas. Nesse sentido, Oliveira (2002) menciona os repórteres em início de carreira, que, devido ao deslumbramento e ao receio de questionar o cientista sobre pontos não compreendidos, podem acabar prejudicando a qualidade e, às vezes, comprometendo a veracidade da informação, por não tê-las compreendido integralmente.

Comentando sobre tais aproximações entre ciência e jornalismo, diz Oliveira (2002, p. 43):

O casamento maior da ciência e do jornalismo se realiza quando a primeira, que busca conhecer a realidade por meio do entendimento da natureza das coisas, encontra no segundo fiel tradutor, isto é, o jornalismo que usa a informação científica para interpretar o conhecimento da realidade.

Mais uma vez, a partir desse pensamento da autora, pode-se ressaltar que, quando o jornalismo científico não traduz para uma linguagem acessível o que foi produzido em linguagem específica, a popularização da ciência não é alcançada. Muitos temas científicos são abstratos ou complexos demais para os leigos entenderem. Para facilitar a compreensão dos leitores, os teóricos do jornalismo científico e os profissionais em atuação na área encorajam a utilização de alguns recursos linguísticos e literários na construção do texto. Tais recursos estilísticos da linguagem, como é o caso das metáforas e das analogias, são empregados com o intuito de aproximar a ciência do cotidiano (e da compreensão) das pessoas, popularizando, assim, o conhecimento especializado.

Além de metáforas e analogias, Burkett (1990, p. 123) sugere o uso da comparação, pois "quando o tamanho relativo éum fator, a compreensão pode ser aumentada fazendo-se comparações com coisas familiares, tais como distâncias entre pontos geográficos, velocidades, pilhas de moedas, grãos de trigo ou areia." Emmatérias de economia, por exemplo, o recurso pode ser usado para ilustrar valores ou comparar moedas estrangeiras. Já em matérias de saúde, para dar a real noção da quantidade de neurônios no cérebro e de sinapses que estes formam.

Para Oliveira (2002), a metalinguagem (linguagem natural ou formalizada que serve para descrever ou falar sobre uma outra linguagem) é um excelente recurso para aproximar o público leigo das informações científicas. Quando as pessoas conseguem associar, diz a autora, um princípio ou uma teoria científica a alguma coisa que lhes é familiar, fica muito mais fácil a compreensão do assunto.

Já Blum e Kundson (apud SMALL, 1997) afirmam que o jornalismo científico tem sua fórmula própria. Além do uso de analogias, metáforas e outros recursos que clarifiquem conceitos difíceis da ciência, o redator deve valer-se da criatividade ao escrever a notícia. Ao contrário dos cientistas, que têm o objetivo de divulgar aspectos específicos de um tema entre um público já informado, o jornalista quer explicar, educar e, principalmente, não tornar a leitura pesada ao leitor. Kreinz e Pavan (apud DESTÁCIO, 2003), por sua vez, lembram que, antes de redigir a matéria, o jornalista deve pensar tanto no veículo que irá divulgar a matéria como no público-alvo daquela determinada publicação. Dependendo do perfil dos leitores, o repórter deverá fornecer mais ou menos detalhes sobre determinado tema, sendo, dessa forma, ou mais específico, ou mais generalista.

Embora o uso de figuras de linguagem seja recomendado por muitos autores, conforme já debatido, esse recurso não é tão frequente nas páginas de $V e j a$ quanto a autora inicialmente imaginava. Elas aparecem em pouco mais de $20 \%$ das matérias de saúde, sendo as mais frequentes as analogias, recurso por meio do qual são traçados pontos de similaridades na comparação entre duas situações distintas. Em matéria sobre medicamentos similares, a analogia foi empregada para expor a necessidade de os medicamentos passarem por testes antes de serem liberados para a comercialização.

Quando os similares foram criados, acreditavase que a mesma quantidade de um princípio ativo levaria à igual efeito no organismo. Sabe-se hoje que a mesma molécula pode não ter o resultado igual se o desenho da estrutura molecular tiver alguma diferença. É como um par de sapatos, em que um pé é igualzinho ao outro. Só que o direito não entra no pé esquerdo, e vice-versa. É sapato, mas, se os pés forem trocados, não dá para andar direito (FRANÇA, 2005, p. 77).

Numa outra reportagem, sobre diabetes, o recurso foi adotado para explicar de que forma são geradas as complicações da doença.

Em grandes quantidades, quando carregada pelo sangue, a insulina age como um arame farpado sendo arrastado pelos vasos 
sangüíneos. Os danos causados por esse processo são os responsáveis pelas principais complicações do diabetes, como retinopatia, insuficiência renal e quadros de gangrena, entre outras (NEIVA, 2005, p. 91).

Além do cuidado com a linguagem, os teóricos também recomendam a humanização dos relatos, uma vez que esta busca aproximar o leitor da informação, para torná-la mais compreensível. Leva-se a informação até o ambiente do leitor, de maneira que ele a sinta e a entenda. Humanizar não significa escrever para o leitor, mas redigir de tal modo que a notícia tenha um sentido para ele. Uma forma simples de humanizar uma história é enquadrar o personagem de um acontecimento no mesmo cenário da maioria dos leitores.

$V$ eja utiliza essa técnica, de forma variada, em 26\% das matérias analisadas. Em algumas reportagens, os personagens são pacientes que vivem aquela situação descrita no texto, como é o caso da matéria sobre cirurgia de redução do estômago, em que são apresentados casos de pessoas que desenvolveram outros tipos de problemas após o procedimento, como depressão, bulimia, anorexia e alcoolismo. Já em outras reportagens, a revista adota a humanização utilizando como gancho algum personagem em pauta na imprensa, como é o caso da matéria sobre os limites da vida e da morte, que teve como ponto de partida o drama da norteamericana Terri Schiavo, que passou 15 anos em estado vegetativo e cujo marido ganhou na Justiça o direito de desligar a máquina que a mantinha viva.

Para humanizar as matérias, Veja também aposta no depoimento de pacientes famosos, como é o caso da reportagem sobre o fim dos mitos sobre o câncer, que reserva grande espaço para o relato do ator Raul Cortez. Em menos destaque, aparecem nesta mesma matéria sobre câncer outras personalidades conhecidas do público, como a apresentadora Ana Maria Braga. A revista ainda utiliza a técnica da humanização para apresentar grupos de pessoas que se encontram numa situação muito particular, como é o caso de um virgem norte-americano que lançou um movimento contra a prática do sexo. Ele aparece em matéria sobre o quoeficiente sexual.

\section{Tamanho das matérias, contextualização e antecedentes}

Quanto ao tamanho das matérias, Costa Bueno (2005) reforça que, para compreender a ciência e a tecnologia, os leitores precisam saber do contexto, ou seja, das implicações sociais, políticas e econômicas. Portanto, o repórter de saúde deve ir além da simples apresentação dos fatos, deve mostrar os antecedentes e as implicações futuras daquela notícia, para que seu leitor possa compreendê-la. Kreinz e Pavan (apud DESTÁCIO, 2003) reforçam essa opinião, afirmando que o jornalista deve buscar a inserção do conhecimento científico na sociedade. O repórter também deve evitar escrever sobre as novidades científicas como descobertas fantásticas, mas que pouco influenciarão a vida das pessoas distantes da pesquisa. O divulgador deve buscar sempre fazer vislumbrar no leitor as perspectivas futuras, para que este enxergue a ciência como essencial ao mundo em que vive e presente ao seu cotidiano. Deve, ainda, apontar os benefícios ou as melhorias que os avanços e os conhecimentos da ciência poderão trazerà sociedade e às pessoas, individualmente, sem espetacularizar a notícia ou trazer falsas esperanças.

Por fim, Friedman et al. (apud O'LEARY, 1986) diz que um bom jornalista científico deve colocar uma certa parcela dos antecedentes da pesquisa na matéria, para ajudar os leitores a compreender o contex to mais amplo no qual aquele tema está inserido, contribuindo assim em apontar suas possíveis consequências na sociedade e o impacto que poderá causar.

Percebe-se, dessa forma, que um texto, por mais bem escrito que seja, não alcançará os objetivos do jornalismo científico se não apresentar os antecedentes ou não contextualizar aquela informação. Um leitor não saberá se um novo mecanismo de ação de determinado medicamento é mais eficiente ou melhor, se não lhe for informado de que forma os medicamentos anteriores funcionavam e o porquê se acredita aquele novo ser uma revolução.

É característica de revistas semanais como $V$ eja dar maior profundidade aos acontecimentos da semana, apresentando suas implicações e seus diferentes ângulos. No caso das reportagens sobre saúde, isso não difere. Em relação ao número de

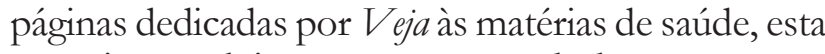
pesquisa concluiu que quase a metade das reportagens analisadas tem duas páginas de extensão. As matérias de apenas uma página representam 18\% do corpus. Matérias de três páginas, por sua vez, respondem por $16 \%$ do total das analisadas. No entanto, no período analisado também foram publicadas matérias bem mais longas, com até nove páginas de extensão. Essas reportagens mais extensas fizeram com que a 
média geral de páginas dedicadas por cada matéria ficasse em torno de três páginas. O tamanho médio de cerca de três páginas é considerado adequado, no sentido de permitir ao repórter apresentar os antecedentes e contextualizar os temas, indo, dessa forma, além da simples notificação. De modo geral, as matérias de Veja contextualizam os assuntos, apresentando seus antecedentes e suas repercussões. Ao interpretar a notícia, o jornalista dá uma nova dimensão narrativa aos assuntos de saúde.

Esse número médio de páginas também permite à publicação espaço suficiente para traduzir para uma linguagem menos especializada o discurso científico. Segundo Hernando (1992), a ciência impõe seus modelos, seus jargões particulares e uma linguagem própria, na maioria das vezes ininteligível para o menos letrado. $O$ trabalho de tradução da mensagem científica é um processo trabalhoso e repetitivo, pois o redator deve ir de uma linguagem a outra até alcançar um texto jornalístico que, preservando os conteúdos da ciência, sejam divulgados numa linguagem compreensível para o público. Em algumas matérias, no entanto, o nome de doenças pouco conhecidas é citado sem o acompanhado de uma explicação. Talvez isso ocorra devido ao fato de essas enfermidades não terem sido o foco principal das matérias em questão. Os termos que geram dúvida foram: colite, retinopatia, pólipos intestinais, listeriose, tricomoníase, icterícia, bilirrubina, toxina botulínica, cretinismo e bócio endêmico.

Embora toda a reportagem tenha de ser escrita de forma clara, a falta de tradução desses termos secundários não compromete o entendimento geral do assunto. De qualquer maneira, $V$ eja deveria se preocupar em traduzi-los, para permitir uma compreensão total da matéria, atingindo os objetivos do jornalismo científico. Para conseguir traduzir temas da área, muitos autores afirmam ser necessário o veículo manter jornalistas especializados, com uma melhor formação em ciência, entre seus profissionais.

\section{Jornalista especializado $\mathrm{x}$ jornalista geral}

Uma das diferenças do jornalismo científico concentra-se entre repórteres de atribuições generalizadas, que são confrontados com temas científicos vez e outra, e aqueles que escrevem sobre ciência o tempo inteiro. Na avaliação de Neto (2004), é muito grande a falta de preparo de jornalistas para tratar de temas científicos. Segundo o autor, existe uma minoria de repórteres especializados, e mesmo esses cometem erros, assim como os próprios cientistas, o que demonstra a necessidade de estudos e atualização constante na divulgação dos fatos.

Friedman et al. (apud SCHNEIDER, 1986) também são favoráveis à especialização dos repórteres, considerando que jornalistas dedicados à cobertura da ciência quase sempre escrevem matérias mais acertadas do que os jornalistas que divulgam temas gerais, pois estes se sentem intimidados diante de dados, jargões e termos técnicos da linguagem científica.

Kreinz e Pavan (apud TUFFANI, 2004) sustentam que essa especialização não precisa ser, necessariamente, formal. Ao contrário, ela pode surgir do próprio interesse e do investimento do profissional, ocorrendo por meio de seminários, leituras, palestras e da própria prática jornalista, assim como acontece com o jornalismo econômico, o jornalismo cultural, o jornalismo político, entre outros. Oliveira (2002) também concorda com os demais autores sobre a especialização do repórter, sendo, entretanto, mais rigorosa nos requisitos básicos necessários para ele conseguir atingir o público com lógica, alcançando os objetivos do jornalismo científico. Para a autora, o repórter, além de bom conhecimento de técnicas de redação, deve ter considerável familiaridade com os procedimentos da pesquisa científica, deve ter conhecimentos de história da ciência, de política científica e tecnológica, e se atualizar constantemente sobre os avanços da ciência, além de manter contato permanente com as fontes especializadas.

A análise da autoria das reportagens analisadas permite identificar que a revista tem por costume reservar temas de medicina a um determinado grupo de repórteres, embora profissionais que escrevam para outras áreas, como economia e política, também escrevam sobre saúde. Cerca de $65 \%$ das matérias são de autoria dos chamados repórteres especializados, ou seja, aqueles que comumente trabalham na área. A principal delas é Paula Neiva, autora de um terço das reportagens. Giuliana Bergamo é autora de $22 \%$ das reportagens, enquanto Anna Paula Buchalla, de 10\%.

Segundo Friedman (apud FRIEDMAN et al., 1986), o tamanho da empresa tem papel fundamental de determinar se há repórteres especializados na redação, e o tipo de reportagem que é realizada. Em geral, revistas e jornais de grande circulação conseguem deslocar repórteres para 
trabalhar em reportagens especiais, dando-lhes mais tempo para tratar de um determinado tema.

Com 1,2 milhão de exemplares vendidos a cada semana, Veja é considerada a revista com maior circulação no país. Com esse tamanho, se imaginaria que mantivesse mais repórteres especializados em sua redação, uma vez que a maioria dos autores defende ser necessário aos jornalistas terem uma melhor formação em ciência para tratar de temas da área. Segundo Kreinz e Pavan (apud HAMBURGUER, 2004), esse conhecimento mais profundo é uma condição sine qua non para ser um bom jornalista científico, embora não seja suficiente. Kreinz e Pavan (apud DESTÁCIO, 2000) também concordam ser necessário ao jornalista que queira escrever sobre ciência e tecnologia se especializar nesse campo do conhecimento humano, para divulgá-lo de maneira correta e eficiente, pois somente entendendo suficientemente do assunto, conseguirá o repórter compreender os temas e transmiti-los de forma clara ao público leigo.

Quanto ao número de matérias assinadas por repórteres especializados, conclui-se que $V$ eja se preocupa em reservar grande parte desses temas a profissionais com maior conhecimento da área, para entregar ao leitor uma reportagem clara. Embora não seja comum, a revista também dá espaço para que os médicos assumam o papel de divulgadores da ciência. Ao longo do período, houve, numa mesma edição, duas matérias em que os autores eram os próprios profissionais da área de saúde. Já numa outra edição da revista, um médico escreveu um artigo de apoio à matéria principal. É provável, no entanto, que em todos os três casos, as matérias tenham sido editadas pela redação, uma vez que os textos apresentavam estilo similar aos demais da publicação.

\section{CONSIDERAÇÕES FINAIS}

Conforme os dados analisados, este estudo conclui que a revista $V$ eja atinge o objetivo do jornalismo científico de levar temas de ciência ao público massivo numa linguagem acessível aos leigos. Para facilitar a compreensão dos leitores, os teóricos do jornalismo científico encorajam a utilização de alguns recursos linguísticos e literários na construção do texto. Para traduzir o conhecimento especializado, a publicação utiliza em um pouco mais de $20 \%$ das matérias de saúde o recurso das figuras de linguagem, sendo a analogia a mais frequente. Nessas reportagens, a publicação alcança a meta de aproximar a ciência da compreensão das pessoas, popularizando, assim, o conhecimento científico.

Além de traduzir o conhecimento especializado, com a ajuda de figuras de linguagem, a publicação apresenta os assuntos de forma contextualizada, indo além da simples notificação, se situando no detalhamento, no questionamento de causa e efeito, na interpretação e no impacto, dando uma nova dimensão narrativa aos assuntos de saúde. Para cada reportagem de saúde, dedica, em média, quase três páginas e, por edição, traz, em média, duas reportagens da área.

Para tornar as informações mais compreensíveis, Veja também utiliza o recurso da humanização, levando os temas até o ambiente do leitor, de maneira que este os sinta e os entenda. A publicação usa essa técnica, de forma variada, em $26 \%$ das matérias analisadas. Nessas reportagens, os personagens são pacientes comuns ou famosos que vivem a situação descrita no texto. Com a preocupação de entregar ao leitor um texto claro e correto, a publicação ainda mantém jornalistas especializados em sua Redação. Tais profissionais respondem por cerca de $65 \%$ das matérias da área. Dessa forma, somente 35\% das reportagens fica a cargo dos chamados jornalistas generalistas.

Com base nesses dados, sobre linguagem adotada, técnicas de humanização, número de páginas dedicadas a temas de saúde e perfil dos repórteres que cobrem os temas, conclui-se que, de forma geral, $V$ eja atinge os objetivos do jornalismo científico.

\section{REFERÊNCIAS}

BURKETT, W. Jornalismo científico: como escrever sobre ciência, medicina e alta tecnologia para os meios de comunicação. Rio de Janeiro: Forense Universitária, 1990.

COSTA BUENO, W. da. Jornalismo científico a distância. Disponível em: <http:/ / comtexto.com.br/ jcaulas_1.htm>. Acesso em: 12 jun. 2005.

DESTÁCIO, M. C. O jornalismo científico sob o olhar da experiência. In: KREINZ, G.; PAVAN, C. (Org.). Os donos da paisagem. São Paulo: NJR/ ECA/USP, 2000. p. 159-168.

Ciência, escrita e responsabilidade. In: KREINZ, G.; PAVAN, C. (Org.). Divulgação científica: reflexões. São Paulo: NJR/ECA/USP, 2003. p. 71-86. 
FRANÇA, R. Uma questão de segurança. Veja, São Paulo, v. 38, n. 1890, p. 76-77, 2005.

FRIEDMAN, S. M. The Journalist's World. In: FRIEDMAN, S. M.; DUNWOODY, S.; ROGERS, C. L. Scientists and journalists: reporting science as news. New York: AAAS, 1986. p. 17-41.

HAMBURGUER, E. Um panorama da difusão da ciência. In: KREINZ, G.; PAVAN, C. (Org.). CONGRESSO INTERNACIONAL DE DIVULGAÇÃO CIENTÍfICA, 1., 2004, São Paulo. Anais... São Paulo: NJR/ECA/USP, 2004. p. 135-139.

Hernando, M. C. Periodismo científico. Madrid: Paraninfo, 1992.

NEIVA, P. A nova química do sangue. Veja, São Paulo, v. 38, n. 1895, p. 104-108, 2005.

NETO, R. B. Precisão e bom senso na construção da notícia. In: CONGRESSO INTERNACIONAL DE DIVULGAÇÃO CIENTÍFICA, 1., 2004, São Paulo. Anais... São Paulo: NJR/ECA/USP, 2004. p. 135-139.

O'LEARY, D. S. Physicians and reporters: conflict, commonalities, and colaboration. In: FRIEDMAN, S. M.; DUNWOODY, S.; ROGERS, C. L. Scientists and journalists: reporting science as news. New York: AAAS, 1986. p. 95-102.

OLIVEIRA, F. de. Jornalismo científico. São Paulo: Contexto, 2002.

SCHNEIDER, S. H. Both sides of the fence: the scientist as source and author. In: FRIEDMAN, S. M.; DUNWOODY, S.; ROGERS, C. L. Scientists and journalists: reporting science as news. New York: AAAS, 1986. p. 215-222.

SMALL, M. F. Scientists who write about science for the public. In: BLUM, D.; KUNDSON, M. A field guide for science writers. Nova York: Oxford University, 1997. p. 57-64.

TUFFANI, M. Divulgação científica e educação. In: KREINZ, G.; PAVAN, C. (Org.). In: CONGRESSO INTERNACIONAL DE DIVULGAÇÃO CIENTÍFICA, 1., 2004, São Paulo. Anais... São Paulo: NJR/ECA/USP, 2004. p. 83-90.

Recebid: 05/05/2009

Received: 05/05/2009

Aprovado: 24/06/2009

Approved: 06/24/2009

Revisado: 03/11/2009

Reviewed: 11/03/2009 